\section{The psychological vs. the ethological rat: Two views of the poison avoidance behavior of the rat compared}

\section{DENIS MITCHELL \\ Psychobiology Program, University of Southern California Los Angeles, California 90007}

In rebuttal to the above comments on our paper (Mitchell, Scott, \& Mitchell, 1977), I would first like to clarify the fundamental differences between my view and that of my adversaries. To do so, I will first outline the pertinent characteristics of each view. I will then briefly compare the two views and finish with specific comments on the present objections to my conclusions raised by my adversaries. As I see them, our theoretical differences are best exemplified by our two views of the rat; the psychological vs. the ethological rat.

\section{The Psychological Rat}

(For reviews, see Revusky \& Garcia, 1970; Garcia \& Ervin, 1968; Garcia, Hankins, \& Rusiniak, 1974; Seligman \& Hager, 1971.) In this view, the poison avoidance behavior of the rat is embodied in the "conditioned taste aversion" paradigm. Many experiments have demonstrated that taste aversions in rats show the following three characteristics:

(1) One-trial learning. When a novel solution is paired with illness, a rat will subsequently avoid the novel solution after only one or two pairings of the solution with illness.

(1) Stimulus specificity. Whereas it is relatively easy to obtain avoidance of "interoceptive" stimuli such as taste or smell when paired with toxicosis, it is apparently difficult to obtain these same results when "exteroceptive" stimuli such as visual or auditory cues are used.

(3) Long-delay learning. Poisoned rats will avoid a novel substance even when long time intervals are interposed between consumption of the novel substance and subsequent illness.

These characteristics are said to distinguish conditioned taste aversions from other forms of learning and have prompted theorists to postulate that the rat has evolved a specialized association mechanism which is extremely fast acting, stimulus specific, and capable of bridging unusually long stimulusconsequence intervals.

\section{The Ethological Rat}

(For more detailed treatment, see Barnett, 1963; Chitty, 1954; Mitchell, 1976; Mitchell, Beatty \& Cox, 1977; Mitchell, Fairbanks, \& Laycock, 1977.) For the ethologist, the poison avoidance behavior of the rat is best exemplified by the behavior of a wild rat confronted with a poison bait. Though the experimental work that has been done on wild rats is less voluminous than the conditioned taste-aversion literature, two central characteristics are evident:

(1) Bait shyness or "learned rejections." "Rats tend to refuse a food which has previously caused illness.

(2) Neophobia or "new object reaction." Rats have an innate (genetically determined) disposition to avoid novel stimuli. Hence, the poison avoidance behavior of the ethological rat is characterized by both an ability to learn associations between foodrelated stimuli and subsequent gastrointestinal consequences and an innate fear of novel stimuli. Note that neophobia is not modality specific; rats naturally avoid both novel foods and novel nonfood objects.

It appears as though rats have evolved a specialized innate behavior (neophobia) on which the association contingencies used in the conditioned taste-aversion paradigm are superimposed. The synergisms and antagonisms between the two processes not only make wild rats extremely difficult to trap or bait, but produce the three characteristics said to distinguish conditioned taste aversions from other forms of learning.

\section{Comparison}

Note that the ethological and the psychological rat have three things in common. First, it is assumed that there is a biological basis for the behavioral propensities of both. The psychological rat's learning ability is offered as evidence that the ability to learn has a biological basis which is subject to the molding of evolution (Garcia, Hankins, \& Rusiniak, 1974). The ethological rat's neophobia is likewise attributed to biological factors which are subject to the influence of evolutionary selection pressures (Barnett, 1963; Chitty \& Southern, 1954; Mitchell, Fairbanks, \& Laycock, 1977).

Second, both the psychological rat and the ethological rat are capable of learning. However, while the psychological rat is an association-learning specialist, the ethological rat is additionally burdened with the necessity of habituating to novel stimuli. Thorpe (1963) has defined habituation as a nonassociative form of learning which is most evident when dealing with innate avoidance behaviors.

Third, novelty plays a central role in the avoidance behavior of both the psychological and the ethological rat. My reading of both the ethological and the psychological literature indicates that when rats are conditioned to avoid novel stimuli, they do not form an association with a previously neutral stimulus. Because of its novelty, the stimulus is not neutral; it already has avoidance-eliciting properties (Mitchell, Fairbanks, \& Laycock, 1977). 
Stripped to its barest essentials, then, the present dispute, as I see it, is this: I cannot accept either the prior or present conclusions of my adversaries, because they do not "fit" with my own observations on the poison avoidance behaviors of wild rats. They cannot accept my conclusions because they insist that they have repeatedly controlled for nonassociative factors and found them to be unimportant. Revusky claims that he is running better controls, Garcia claims he ran the same controls as my colleagues and I and found no effect, and Smith claims that neophobia controls are superfluous when a long-term, two-bottle test is used.

In his comments, Smith (1978) suggests that procedural differences among the various studies we are citing are a significant cause of our disagreements. I could not agree more. But, while he suggests that a long-term test will obviate the need for neophobia controls, I believe that such tests only obscure underlying mechanisms. I doubt very much if he could use his 24-h test on wild or even wild $\times$ domestic strains and still fail to find an expression of neophobia (Mitchell, 1976; Mitchell, Fairbanks, \& Laycock, 1977). However, for the sake of argument, suppose that one does as Smith suggests and uses a long-term test that reveals no neophobia or habituation in the control groups. Does this failure to observe a behavioral manifestation of neophobia and its subsequent habituation in the control groups necessarily prove that they are not involved in the avoidance behavior of the experimental groups? In previous papers, we have shown that lack of a preference for one food source over another does not mean that rats cannot distinguish between the two on the basis of novelty alone. For example, after considerable habituation to both a familiar and a novel food source, even laboratory rats still retain a neophobic disposition toward the more novel of the two, as evidenced by the ability of a noncontingent poisoning to either reinstate or prolong the avoidance of the more novel food source (Mitchell, Hoch, \& Fitzsimmons, 1975; Mitchell, Kirschbaum, \& Perry, 1975).

In one of these experiments (Mitchell, Kirschbaum, \& Perry, 1975; Experiment 2), we found that when we paired consumption from a familiar food container with toxicosis and subsequently offered the animals a choice between the familiar and a novel container, the rats did not avoid the stimulus paired with poisoning (the familiar container), but the more novel one. In addition to our own data, several authors, who include among their number at least one of my present adversaries, have reported that within the context of the conditioned taste-aversion paradigm the relative novelty of a given substance is a better predictor of preference following treatment than are the contingencies of the poisoning (Revusky
\& Bedarf, 1967; Richter, 1953; Wittlin \& Brookshire, 1968). I submit that these are precisely the effects one who was looking for a manifestation of neophobia in the contingently poisoned experimental groups would expect.

I cannot therefore agree with Smith's assertion that "nonassociative factors do not matter when a long-term test is used." In my view, whether a given experimental procedure is sensitive enough to detect a given mechanism (neophobia) does matter, especially when one concludes that the only thing that matters is a mechanism not excluded by the procedure (association learning).

My own reading of the literature has convinced me that at the very least there has been a certain cavalier attitude toward noncontingently poisoned control groups within the context of conditioned taste aversions. Smith's reason for omitting these controls from one of the papers we cited (Smith \& Roll, 1967) is a case in point. In his own words: "We did not because there was such a history in our laboratory of that control group showing no evidence of conditioning." Clearly this statement was then, and is now, more true of sham controls (animals given a sham injection after drinking saccharin) than it was or is of noncontingently poisoned controls, but the former controls were included while the latter were seen as unnecessary (Smith \& Roll, 1967). If sham controls are routinely included in spite of the fact that they virtually never show a saccharin avoidance, why are noncontingently poisoned controls, which often show a saccharin avoidance, so often omitted?

Garcia's (1978) "coy comments on our paper (Mitchell, Scott, \& Mitchell, 1977) leave little doubt that he is defending the view that a flavor-illness association alone can account for the avoidance behavior seen in the groups presented with saccharin prior to treatment. However, in his above comments, he fails to acknowledge the fact that the group of animals which was poisoned $6 \mathrm{~h}$ after drinking saccharin subsequently showed an extinction curve that was not significantly different from those shown by the groups presented with water prior to treatment.

Though he is willing to admit that neophobia is a "real" phenomenon and that the animals given water prior to treatment show both neophobia and its subsequent habituation, Garcia evidently believes that neophobia is somehow turned off when one initiates a conditioning procedure. I cannot agree with the implication that when an association learning mechanism is used, it completely replaces nonassociative mechanisms. The behavioral classification of learning into various distinct forms, such as habituation, association learning, latent learning, and insight learning, does not necessarily mean that the underlying processes are mutually exclusive. In the great 
from reinforcement than CS1 and, hence, it is more inhibitory. And, even granting the possibility of CS2-CS1 association, it is not altogether certain that one should expect CS1 responding to exceed CS2 responding; perhaps, if the animal anticipates both CS1 and the US, it should respond more to CS2 than to CS1 (CS2 has two sources of excitation, CS1 has only one).

Although we have emphasized the fact that our methods isolate the association of conditioned stimu$\mathrm{li}$, it is clear that these associations would never have been manifested were it not for the fact that food delivery followed CS2-CS1 pairings. With our procedures, food presentation is necessary for producing keypecking. The question of whether food presentation is also necessary for association formation between CS2 and CS1 is not answered by the present experiments (see Browne, 1976, and Zentall \& Hogan, 1975, for evidence pertinent to this question with first-order conditioning procedures). Nor is the equally interesting question of whether the associations formed involve sensory-sensory or sensorymotor neural connections (see Rashotte, Griffin, \& Sisk, 1977, and Rescorla, 1973, 1977, for data bearing on this question). We hope that our methods will be as helpful in elucidating these issues as they were in producing reliable CS-CS conditioning effects.

And finally, the present results indicate that not only are associations between conditioned stimuli rapidly formed, but also that when formed, these associations are quite stable and persistent. This contrasts markedly with the results of earlier studies in which the assessment of association formation took place under conditions not involving biologically significant stimulation. Characterizations of associations between biologically insignificant or conditioned stimuli as weak and unstable (Asratyan, 1965) should certainly be reconsidered in light of our results and those of others (especially Rescorla, 1973, 1977).

\section{REFERENCES}

Asratyan, E. A. Compensatory adaptations, reflex activity, and the brain. Oxford: Pergamon Press, 1965.

Browne, M. P. The role of primary reinforcement and overt movements in autoshaping in the pigeon. Animal Learning $\&$ Behavior, 1976, 4, 287-292.

Mackintosh, N. J. The psychology of animal learning. London: Academic Press, 1974.
Newlin, R. J., \& Lolordo, V. M. A comparison of pecking generated by serial, delay, and trace autoshaping procedures. Journal of the Experimental Analysis of Behavior, 1976, 25, 227-241.

Rashotte, M. E., Griffin, R. W., \& Sisk, C. L. Second-order conditioning on the pigeon's keypeck. Animal Learning \& Behavior, 1977, 5, 25-38.

Razran, G. Mind in evolution: An East-West synthesis of learned behavior and cognition. Boston: Houghton-Mifflin. 1971.

Rescorla, R. A. Second-order conditioning: Implications for theories of learning. In F. J. McGuigan \& D. B. Lumsden (Eds.), Contemporary approaches to conditioning and learning. Washington, D.C: Winston, 1973. Pp. 127-150.

Rescorla, R. A. Pavlovian second-order conditioning: Some implications for instrumental behavior. In $\mathrm{H}$. Davis \& H. M. B. Hurwitz (Eds.), Operant-Pavlovian interactions. Hillsdale, N.J: Erlbaum, 1977. Pp. 133-164.

RiccI, J. A. Key pecking under response-independent food presentation after long simple and compound stimuli. Journal of the Experimental Analysis of Behavior, 1973, 19. 509-516.

Rudenko, L. P. On the functional structure of conditioned reflexes to serial stimuli in dogs. Acta Neurobiologiae Experimentalis, 1974, 34, 69-79.

SEIDEL R. J. A review of sensory preconditioning. Psychological Bulletin, 1959, 56, 58-73.

Sutherland, N. S., \& Mackintosh, N. J. Mechanisms of animal discrimination learning. New York: Academic Press, 1971.

Tномpson, R. F. Sensory preconditioning. In R. F. Thompson \& J. F. Voss (Eds.), Topics in learning and performance. New York: Academic Press, 1972. Pp. 105-129.

Wasserman, E. A. The effect of redundant contextual stimuli on autoshaping the pigeon's keypeck. Animal Learning \& Behavior, 1973, 1, 198-206

Wasserman, E. A. Stimulus-reinforcer predictiveness and selective discrimination learning in pigeons. Journal of Experimental Psychology, 1974, 103, 284-297.

Wasserman, E. A., \& Anderson, P. A. Differential autoshaping to common and distinctive elements of positive and negative discriminative stimuli. Joumal of the Experimental Analysis of Behavior, 1974, 22, 491-496.

Wasserman, E. A., Franklin, S. R., \& Hearst, E. Pavlovian appetitive contingencies and approach versus withdrawal to conditioned stimuli in pigeons. Journal of Comparative and Physiological Psychology, 1974, 86, 616-627.

Wasserman, E. A., \& McCracken, S. B. The disruption of autoshaped key pecking in the pigeon by food-tray illumination. Journal of the Experimental Analysis of Behavior, 1974, 22. 39-45.

Wickens, D. D. Classical conditioning, as it contributes to the analyses of some basic psychological processes. In F. J. McGuigan \& D. B. Lumsden (Eds.), Contemporary approaches to conditioning and learning. Washington, D.C: Winston, 1973. Pp. 213-243.

Zentall, T. R., \& Hogan, D. E. Key pecking in pigeons produced by pairing keylight with inaccessible grain. Journal of the Experimental Analysis of Behavior, 1975, 23, 199-206.

(Received for publication July 8, 1977; revision accepted September 7, 1977.) 
determine to what extent naive animals will avoid the novel substance in the absence of any opportunity to form an association or a preference (Mitchell, Parker, \& Johnson, 1976; Mitchell, Scott, \& Mitchell, 1977). That these are important considerations was dramatically demonstrated to my colleagues and me when we made an unsuccessful attempt to compare the performance of laboratory and wild strains in a conditioned taste-aversion experiment. We found that it was more difficult to "condition" an avoidance of a novel food in wild rats than in laboratory rats simply because a significant proportion of the wild rats refused to sample the novel food before they were due to be poisoned. We ultimately gave up the attempt and concentrated, instead, on devising methods of detecting and manipulating the neophobia of laboratory rats (Mitchell, 1976; Mitchell, Hoch, \& Fit/simmons, 1975; Mitchell, Scott, \& Williams, 1973) and of overcoming the neophobia of wild rats (Mitchell, Fairbanks, \& Laycock, 1977).

I submit that, in addition to being an important reason for the present dispute, the procedural biases and inconsistericies that characterize the taste aversion paradigm at this time indicate that we need more objective methods and a better understanding of the role of nonasscilative factors before we can conclude that the peculiar properties of conditioned taste aversions are ll:e to the evolution of a specialized association mesi anism.

\section{REFERENCES}

BARnetT. S. A. The rat: $A$ study in behaviour. London: Methuen, 1963.

ChITTY. D. (Ed.) Control of rats and mice (Vols. $1 \&$ 2). Oxford: Clarendon Press. 1954.

Chitty. D., \& Southern, N. H. Control of rats and mice. London: Oxford University Press, 1954.

Garcia, J. Mitchell. Scott. and Mitchell are not supported by their own data. Animal Learning \& Behavior. 1978, 6, 116.

Garcia, J., \& ERvin, F. R. Gustatory-visceral and telereceptor cutaneous conditioning-adaptation in internal and external milieus. Communications in Behavioral Biology, 1968, I(Part A), 389-415.

Garcia, J.. Hankins, W. G., \& Rusiniak, W. Behavioral regulation of the milieu interne in man and rat. Science, 1974, 185. 824-831.

Mitchell, D. Experiments on neophobia in wild and laboratory rats: A reevaluation. Journal of Comparative and Physiological Psychology, 1976. 90, 190-197.
Mitchell. D. Reply to Revusky. Animal Learning \& Behavior. 1977, 5. 321.322.

Mitchell. D.. Beatty. E. T., \& Cox, P. K. Behavioral differences between two populations of wild rats: Implications for domestication research. Behavioral Biology, 1977, 19. 206-216.

Mitchell, D., Fairbanks, M., \& Laycock, J. D. Suppression of neophobia by chlorpromazine in wild rats. Behavioral Biology, 1977, 19. 309-323.

Mitchell. D.. Носн. N. E., \& Fitzsimmons, M. Effects of neophobia sensitization on the rat's preference for earned food. Behavioral Biology, 1975, 13, 519-525.

Mitchell, D., Kirschbaum. E. H.. \& Perry, R. L. Effects of neophobia and habituation on the poison-induced avoidance of exteroceptive stimuli in the rat. Journal of Experimental Psychology: Animal Behavior Processes, 1975, 104. 47-55.

Mirchell. D., Parker, L. F., \& Johnson, R. Absence of a generalization decrement in the poison-induced avoidance of interoceptive stimuli in the rat. Physiological Psychology, $1976,4,121.123$.

Mitchell, D., Scott. D. W., \& Mitchell, L. K. Attenuated and enhanced neophobia in the taste-aversion "delay of rein. forcement" effect. Animal Learning \& Behavior, 1977, 5. 99-102.

Mitchell, D., ScotT, D. W., \& Williams, K. D. Container neophobia and the rat's preference for earned food. Behavioral Biology, 1973, 9. 613-624.

Revusky, S. H. Aversion to sucrose produced by contingent $\mathrm{x}$-irradiation. Journal of Comparative and Physiological Psychology, 1968, 65, 17-22.

Revusky. S. H. Correction of a paper by Mitchell. Scott, and Mitchell. Animal Learning \& Behavior, 1977, 5. 319.

Revusky, S. H. Reply to Mitchell. Animal Leaming \& Behavior. 1978, 6, 119-120.

Revusky, S. H., \& Bedarf, E. W. Association of illness with prior ingestion of novel foods. Science, 1967, 155, 219-220.

Revusky, S. \& \& Garcia, J. Learned associations over long delays. In G. H. Bower (Ed.), The psychology of learning and motivation: Advances in research and theory (Vol. 4). New York: Academic Press, 1970

RichTER, C. P. Experimentally produced behavior reactions to food poisoning in wild and domesticated rats. Annals of the New York Academy of Sciences, 1953, 56, 225-239.

Seligman, M. E. P., \& Hager, J. L. (Eds.), Biological boundaries of learning. New York: Appleton-Century-Crofts. 1971.

Smith, J. C. Comment on paper by Mitchell, Scott. and Mitchell. Animal Learning \& Behavior, 1978, 6, 117-118.

SMITH, J. C., \& Roll, D. L. Trace conditioning with $x$-rays as aversive stimulus. Psychonomic Science, 1967. 9, 11-12.

Thorpe, W. H. Learning and instinct in animals. London: Methuen. 1963.

Wittlin, W. A., \& Brookshire, K. H. Apomorphine-induced conditioned aversion to a novel food. Psychonomic Science. 1968. 12. 217-218.

(Received for publication October 5. 1977; accepted October 20, 1977.) 